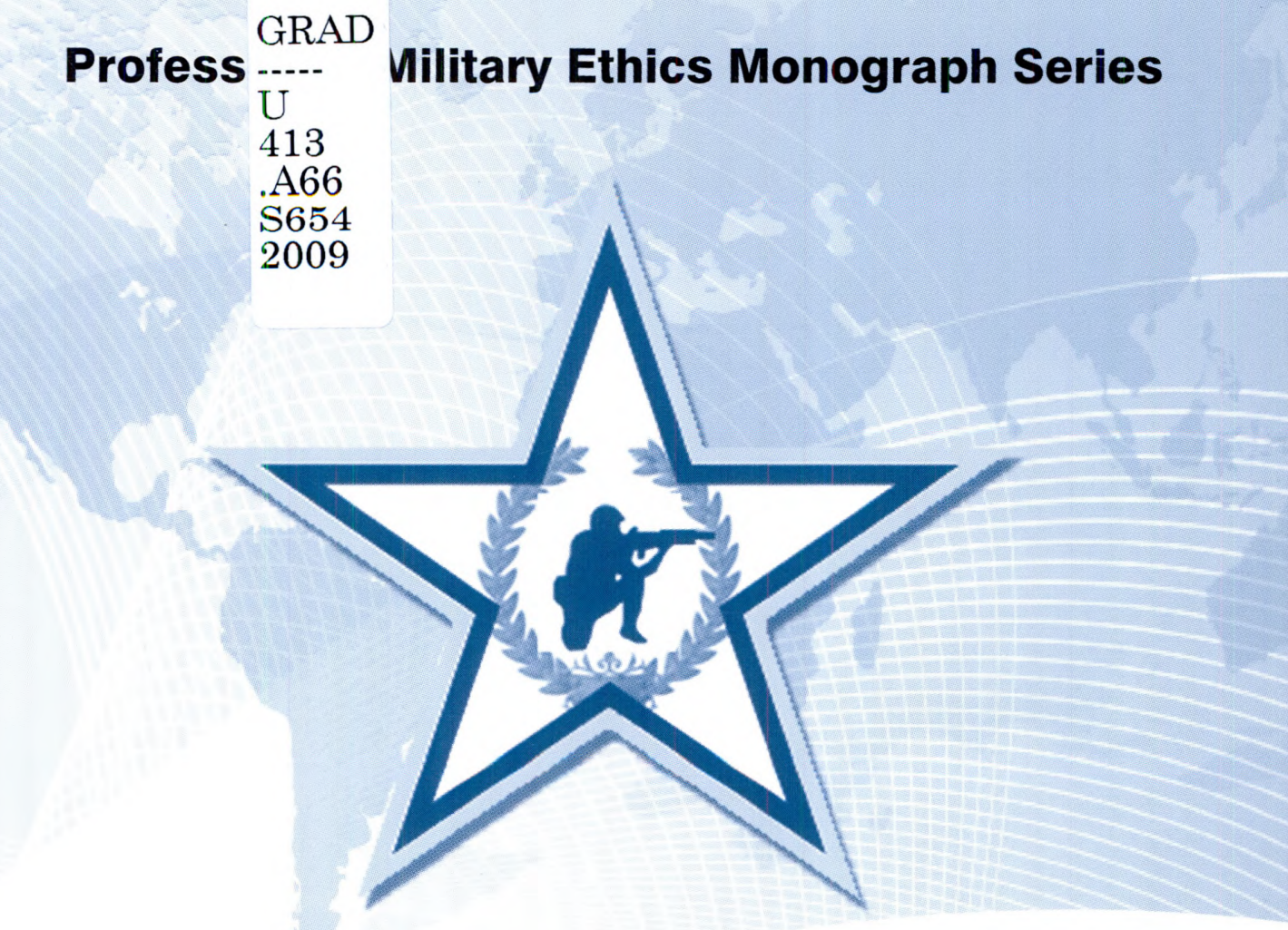

Volume 1

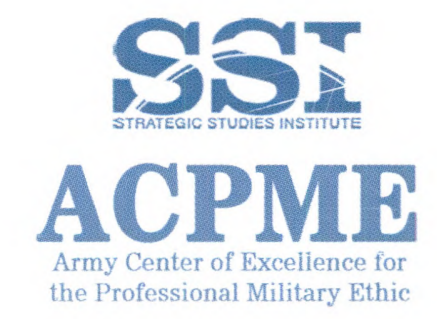

\title{
THE ARMY'S PROFESSIONAL MILITARY ETHIC IN AN ERA OF PERSISTENT CONFLICT
}

Don M. Snider

Paul Oh

Kevin Toner

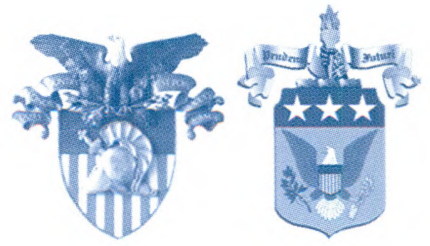

